Running Head: Beliefs about brain injury

\title{
Beliefs about brain injury in Britain
}

\section{Rowena CG Chapman \& John M Hudson}

Department of Psychology, University of Lincoln, Lincoln, UK

\author{
Corresponding Author \\ John M Hudson \\ Department of Psychology \\ Faculty of Health, Life and Social Sciences \\ Brayford Pool \\ Lincoln LN6 7TS \\ UK \\ E-mail: jhudson@lincoln.ac.uk \\ Phone: + 44 (0) 1522886782 \\ FAX: + 44 (0) 1522886026
}




\begin{abstract}
Primary objective: Surveys have revealed that a high proportion of the public in the US and Canada hold misconceptions pertaining to the sequelae of brain injury. This study examined whether similar misconceptions are endorsed by adults in Britain.

Research design: Survey
\end{abstract}

Methods and procedures: Three hundred and twenty two participants completed a 17 item questionnaire containing true or false statements about general knowledge of brain injury, coma and consciousness, memory impairments and recovery.

Main outcomes and results: Regardless of age, sex, level of education and familiarity with brain injury, participants held mistaken beliefs about consciousness, were inclined to underestimate the extent of memory deficits, and were unaware that patients are more vulnerable and less resistant to further injury. A large proportion of respondents indicated that their knowledge of brain injury had been derived from the popular media. Conclusions: Similar misconceptions to those reported in previous studies exist in Britain. Notably in this study these misconceptions were endorsed by a greater percentage of respondents. Greater public awareness is needed for decisions concerning funding and patient care. It is therefore important for health care professionals and public health campaigns to dispel myths about brain injury.

Keywords: Brain injury; misconceptions; media influence 


\section{Introduction}

Brain injury is the worlds leading cause of death and disability [1]. According to figures from the organisation Headway [2], in the UK over 140000 people are admitted to hospital due to brain injury every year, and over half the number of UK deaths in people below 40 years of age are caused by brain injury. Survivors of brain injury have a normal life expectancy and the number of survivors living with a long term disability as a consequence of brain injury in the UK alone is around 500000 [3].

Despite the prevalence and severe consequences of brain injury, research suggests that the general public hold numerous misconceptions pertaining to its physical, cognitive and behavioural sequelae. Gouvier et al. [4] developed a questionnaire consisting of 25 statements designed to examine knowledge about brain injury. They found that almost half of their sample held misconceptions relating to the nature of unconsciousness, the recovery process and the impact of brain injury on cognitive status. Willer et al. [5] and Guilmette and Paglia [6] revealed similar misconceptions using a modified version of the original Gouvier et al. questionnaire. In both these surveys a high proportion of participants believed that survivors of brain injury only suffer temporary cognitive deficits, and believed that even severe brain injury would not prevent someone from returning to their previous employment.

Misconceptions about brain injury are not only displayed by the general public. Springer et al. [7] reported that family members of patients who had sustained brain injury held misconceptions, particularly concerning memory deficits, unconsciousness and recovery. Additionally, Swift and Wilson [8] showed that health professionals who did not specialise in brain injury also endorsed misconceptions relating to recovery and 
cognitive impairment, and further held misconceptions regarding the prognosis of brain injury.

Recently, Hux et al. [9] sought to examine whether health campaigns had improved the US public’s understanding about the sequelae of brain injury previously reported by Gouvier et al. On the positive side, they reported marked improvements pertaining to general knowledge about brain injury. However, misconceptions relating to unconsciousness, memory impairment and the recovery process were still prevalent in all sectors of the community. Although Hux et al. did not methodically derive information relating to the source of knowledge about brain injury, they speculated on the basis of comments made by respondents that the popular media is influential in fostering erroneous perceptions of brain injury. Consistent with this view, studies by Casarett et al. [10], Wijdicks [11] and a review by Baxendale [12] have indeed shown that the sequelae of brain injury portrayed by the media can be markedly inaccurate.

To date, surveys examining misconceptions about brain injury have been conducted in the US and Canada. The aim of the present study is to test the hypothesis that similar misconceptions that have been reported in those studies are also endorsed by adults in Britain. We also examine whether knowledge of brain injury in Britain differs as a function of age, education and familiarity with brain injury. Further, we test the hypothesis that the media is an influential source of information from which many people derive their understanding of brain injury.

\section{Method}


Participants: Study participants were 322 individuals recruited through snowball sampling. These consisted of 125 (39\%) male adults and 187 (58\%) female adults, 10 (3\%) respondents omitted details of sex. The mean age of the sample was 48 years (SD = 18); 73 (23\%) were between 18-29 years; 37 (11\%) were between 30-39 years; 61 (19\%) were between 40-49 years; 73 (23\%) were between 50-59 years; 47 (15\%) were between 60-69 years; 31 (10\%) were aged over 70 years. A third of the sample (33\%) knew either a relative or close friend who had suffered brain injury; 57 (18\%) participants had personally sustained brain injury.

The educational level of the sample was wide ranging; 8 (2\%) of participants left school before the age 15; 51 (16\%) had achieved school level qualifications e.g. O level, GCSE, City \& Guilds; 55 (17\%) had achieved college level qualifications e.g. A level, Intermediate GNVQ, RSA Advanced Diploma; 25 (8\%) had achieved higher college level qualifications e.g. HND, HNC, RSA Higher Diploma; 80 (25\%) had gained a degree and 93 (29\%) had obtained a higher degree or postgraduate qualification; 10 (3\%) respondents omitted details of education.

Questionnaire: The questionnaire consisted of the 17 true or false statements (see Table 1) deployed by Hux et al. Items 1-4 relate to general knowledge about brain injury; items 5-7 relate to unconsciousness and coma; items 8-11 relate to memory; items 12-17 relate to brain injury and recovery. Items regarding demographic information and details of respondents' personal experience of brain injury were also included. The questionnaire concluded with an open ended question asking respondents where they had learned about head injuries. 
Procedure: Participants were asked to complete a questionnaire designed to examine the public's perception of head injury and recovery. They were informed that the questionnaire would take between 5-10 minutes to complete and included 17 brief statements which they would be required to decide was either "true" (T) or "false" (F). Participants were assured that all data would remain anonymous and that they could withdraw from the survey at any point. All participants gave informed consent prior to participating in the study. No incentives were provided. Upon completion all questionnaires were returned either by post, email or personally to the first author who entered responses into a database.

Data analysis: The proportion of participants with correct and incorrect responses to the 17 statements constituted the dependent measure of accurate and mistaken perceptions of brain injury and its sequelae respectively. Chi-square analyses were performed on these data to compare differences between respondent sub-groups, and to compare responses from this survey to those reported by Hux et al.

\section{Results}

The percentage of participants who responded correctly to each of the 17 statements is displayed in table 1 . Overall, it is notable that the participants in this study held similar misconceptions about brain injury and its sequelae as those who participated in the Hux et al. survey.

Insert table 1 about here

Moreover, comparing the data between these two studies shows a greater percentage of the present respondents endorsed misconceptions relating to the following 
areas: general knowledge of brain injury (items $1-4$ mean $=20.4 \%$ vs. $8.3 \% ; X^{2}=10.53$, $\mathrm{P}=0.001$ ); consciousness and coma (items $5-7$ mean $=60.6 \%$ vs. $43.8 \% ; X^{2}=29.24, P=$ 0.0001 ) and memory (items $8-11$ mean $=63.4 \%$ vs. $54.7 \% ; X^{2}=11.96, P=0.0005$ ). The difference in knowledge of recovery (items $12-17$ mean $=48.2 \%$ vs. $44.3 \% ; \mathrm{X}^{2}=2.79, \mathrm{P}$ $=0.095$ ) was less pronounced overall.

Comparisons between grouping factors, showed males responded more accurately than females to statement $2\left(76.2 \%\right.$ vs. 58.3\%; $\left.\mathrm{X}^{2}=13.81, \mathrm{P}=0.003\right)$ and statement 7 (51.2\% vs. $\left.37 \% ; X^{2}=9.48, P=0.024\right)$.

Participants were divided into three age bands; young (19-39 years), middle-aged (40-59 years) and older adults (over 60 years). This analysis showed that older adults (51.3\%) were more accurate at correctly judging statement 11 to be true (middle-aged = $37.3 \%$; young $\left.=31.8 \% ; \mathrm{X}^{2}=21.14, \mathrm{P}=0.002\right)$.

Educational level was divided into two categories for analysis, participants who held at least a first degree (55.5\%) and participants without a degree (45.5\%). A significant difference was only observed for statement 9, a greater percentage of respondents with a degree answered this statement correctly (82.6\% vs. $63.9 \% ; \mathrm{X}^{2}=$ 14.86, $\mathrm{P}=0.001)$.

To examine whether familiarity with brain injury survivors is associated to ones beliefs about brain injury and its sequelae, two questions at the beginning of the survey asked respondents to firstly indicate whether they had personally suffered a head injury, and secondly to indicate if they knew a close friend or relative who had suffered a head injury. The majority of participants answered 'no' to both these questions (60.1\%); 10\% answered 'yes' to both; 7.3\% had suffered a head injury themselves but didn’t know a 
relative or friend who had; $22.6 \%$ had not suffered a head injury themselves but knew a relative or friend who had sustained a head injury. Chi-square analysis showed that there was no association between personal experience of brain injury and knowledge of brain injury $\left(\mathrm{X}^{2}=3.44, \mathrm{P}=0.752\right)$.

Finally, 301 out of 322 participants (94\%) provided responses to the open ended question “Where have you learnt about head injuries?” Seven broad sources of information were identified. A large percentage of respondents indicated that their knowledge of brain injury had been derived from the 'media' e.g. TV, newspapers (38\%). This was followed by, ‘personal experience’ (17.3\%); ‘don’t know’ (16.9\%); 'general knowledge’ e.g. life experience (16.6\%); ‘word of mouth’ e.g. conversation, hearsay (10.6\%); 'professional experience’ e.g. nursing, army services (6.6\%) and ‘first aid course’ $(3.7 \%)$.

\section{Discussion}

The results of this study show that misconceptions about brain injury that have been endorsed in several studies conducted in the US and Canada $[4,6,8,9]$ are also endorsed by the general public in Britain. Indeed, the magnitude of misconceptions held by respondents in the present study were on the whole markedly greater than those reported previously for issues pertaining to general knowledge of brain injury, consciousness and coma and memory deficits. Respondents in this survey are all of course potential victims of brain injury themselves, either directly as a patient, or indirectly through relations with others. From either of these perspectives, endorsement of the misconceptions that have been evidenced may have a negative impact on attitudes 
towards rehabilitation and recovery. For example, patients who are unaware that brain injury commonly produces memory deficits; or believe that complete recovery from a severe head injury is possible as long as the individual works hard at recovery, may have unrealistic expectations of a full recovery. They may therefore experience lower self esteem, increased levels of anxiety, depression and frustration if their perceived expectations of recovery are not achieved. Acquaintances who share similar misconceptions, may view lapses in memory less sympathetically, and feel frustrated too, believing that the patient could put more effort into recovering [14]. More catastrophic ramifications could ensue if patients or caregivers are unaware that brain injury increases the probability of receiving subsequent brain injury, and that the consequences of repetitive injury while still symptomatic can result in malignant cerebral oedema, which is potentially fatal [13].

Hux et al. speculated that popular forms of media play a role in perpetuating misconceptions about brain injury; and in this survey a large number of participants indicated that their knowledge of brain injury had in fact been informed by the media. An interesting review by Baxendale [12] describes how misconceptions about amnesia have historically been portrayed in movies. For example, a large percentage of participants in this survey endorsed the view that brain injury commonly produces a profound retrograde amnesia but not the ability to learn new information, in movies this is a popular scenario (Finding the Way Home; Matrimonial Bed; The Bourne Identity). The notion that amnesia can be cured by a second brain injury is another implausible but popular scenario portrayed in movies (Overboard; Tarzan the Tiger). In addition to improbable patterns of amnesia, Baxendale argues that some movies depict memory impairments which are 
actually neurologically impossible (Clean Slate; 50 First Dates), while only a very small number in fact present an accurate account of amnesia (Finding Nemo; Memento). The primary aim of movies, TV dramas and soap operas is of course to entertain and not inform. However, research into the concept of dramatic licence by Garfield and Millwood Hargrave [15] showed that although the British public accept this tenet and do not expect to be educated through these medium, they do expect a degree of verisimilitude especially pertaining to medical issues. According to these authors, 'When participants were asked if they had learnt anything from a drama, most spontaneously said no or they did not watch drama for information. However there were comments which implied that viewers may learn or gather information subconsciously, raising concerns about the implications of inaccurate information’ (p.25).

In sum, despite the prevalence of brain injury the British public endorse a number of misconceptions pertaining to its sequelae. In particular there appears to be: a) a misunderstanding of the nature of unconsciousness; b) an underestimation of the memory deficits that commonly follow brain injury; and c) inaccuracies relating to the complexity of the recovery process and risks associated with successive brain injury. Endorsing these misconceptions - which for many appear to be at least partly influenced by how the popular media portrays brain injury, can impede the recovery process and exacerbate the psychological symptoms experienced by both patients and family members. It is important that neuropsychologists and other health professionals recognise that the general public may have mistaken beliefs about brain injury, and endeavour to dispel these myths in the clinic and through health campaigns. Greater public awareness is critical for patient care and for decisions concerning the allocation of financial resources. 
Declaration of interest: A close relative of the first author has sustained brain injury. 


\section{References}

[1] International Brain Injury Association [Internet]. Brain injury facts. Available online at: http://www.internationalbrain.org/?q=Brain-Injury-Facts accessed 20 July 2009.

[2] Headway. Key facts. Available online at:

http://www.headway.org.uk/sitePages.asp?step=4\&contentID=1520\&navID=159 accessed 20 July 2009.

[3] Daisley A, Tams R, Kischika U. Head Injury: The Facts. Oxford University Press, New York; 2009.

[4] Gouvier WD, Prestholdt PH, Warner MS. A survey of common misconceptions about head injury and recovery. Archives of Clinical Neuropschology 1988;3:331-343.

[5] Willer B, Johnson WE, Rempel RG, Linn, R. A note concerning misconceptions of the general public about brain injury. Archive of Clinical Neuropsychology 1993;8:461465.

[6] Guilmette TJ, Paglia MF. The public’s misconceptions about trauma brain injury a follow up study. Archives of Clinical Neuropsychology 2004;19:183-189. 
[7] Springer JA, Farmer JE, Bouman DE. Common misconceptions about traumatic brain injury among family members of rehabilitation patients. Journal of Head Trauma Rehabilitation 1997;12:41-50.

[8] Swift TL, Wilson SL.(2001) Misconceptions about head injury among the general public and non-expert health professionals: an exploratory study. Brain Injury 2001;15:149-165.

[9] Hux K, Schram, CD, Goeken T. Misconceptions about brain injury: a survey replication study. Brain Injury 2006;20:547-553.

[10] Casarett D, Fishman JM, MacMoran, HHJ, Pickard A, Asch DA. Epidemiology and prognosis of coma in daytime television dramas. British Medical Journal 2005;331:15371539.

[11] Wijdicks EFM. Why the new HBO Documentary, 'Coma' is Disappointing. Neurology Today 2007:28-29.

[12] Baxendale S. Memories aren’t made of this: amnesia at the movies. British Medical Journal 2004;329:1480-1483.

[13] Saunders RL, Harbaugh RC. The second impact in catastrophic contact-sports head trauma. Journal of the American Medical Association 1984;252:538-539. 
[14] Lezak MD. Psychological implications of traumatic brain damage for the patient's family. Rehabilitation Psychology 1986;31:241-250.

[15] Gatfield L, Millwood Hargrave A. Dramatic Licence: Fact or Fiction? Broadcasting Standards Committee 2003. 


\section{Table 1}

Percentage of participants who answered questionnaire items accurately in Britain and US (Hux et al. 2006)

\begin{tabular}{|c|c|c|c|}
\hline Questionnaire item (correct true and false responses are in parentheses) & Britain & US & $\mathrm{P}=$ \\
\hline A head injury can cause brain damage even if the person is not knocked out. (T) & 95.00 & 98.74 & .630 \\
\hline $\begin{array}{l}\text { Whiplash injuries to the neck can cause brain damage even if there is no direct blow to the head. } \\
\text { (T) }\end{array}$ & 64.80 & 90.25 & .0002 \\
\hline Emotional problems after head injury are usually not related to brain damage. $(\mathrm{F})$ & 67.80 & 83.65 & .018 \\
\hline Most people with brain damage look and act disabled. (F) & 91.70 & 94.03 & .743 \\
\hline When people are knocked unconscious, most wake up shortly with no lasting effects. (F) & 22.90 & 51.89 & .0001 \\
\hline $\begin{array}{l}\text { 6. Even after several weeks in a coma, when people wake up, most recognise and speak to others } \\
\text { right away. (F) }\end{array}$ & 53.20 & 76.42 & .0001 \\
\hline People in a coma are usually not aware of what is happening around them. $(\mathrm{T})$ & 42.20 & 40.25 & .712 \\
\hline $\begin{array}{l}\text { After head injury, people can forget who they are and not recognise others, but be normal in } \\
\text { every other way. (F) }\end{array}$ & 8.60 & 6.60 & .391 \\
\hline $\begin{array}{l}\text { 9. Sometimes a second blow to the head can help a person remember things that were forgotten after } \\
\text { a first blow to the head. (F) }\end{array}$ & 74.10 & 71.38 & .643 \\
\hline 10. People with amnesia for events before the injury usually have trouble learning new things too. (T) & 31.20 & 51.89 & .0001 \\
\hline $\begin{array}{l}\text { 11. After head injury, it is usually harder to learn new things than it is to remember things from } \\
\text { before the injury. }(\mathrm{T})\end{array}$ & 32.60 & 51.52 & .0003 \\
\hline 12. How quickly a person recovers depends mainly on how hard they work at recovering. $(\mathrm{F})$ & 50.20 & 47.48 & .572 \\
\hline 13. People who have had one head injury are more likely to have a second one. (T) & 10.60 & 32.08 & .0001 \\
\hline $\begin{array}{l}\text { 14. A person who has recovered from a head injury is less able to withstand a second blow to the } \\
\text { head. (T) }\end{array}$ & 48.50 & 70.13 & .0003 \\
\hline 15. Once a recovering person feels 'back to normal', the recovery process is complete. $(F)$ & 91.70 & 97.48 & .464 \\
\hline 16. It is good advice to remain inactive during recovery. $(\mathrm{F})$ & 83.10 & 60.06 & .0006 \\
\hline $\begin{array}{l}\text { 17. Complete recovery from a severe head injury is not possible, no matter how badly the person } \\
\text { wants to recover. }(\mathrm{T})\end{array}$ & 26.90 & 27.99 & .763 \\
\hline
\end{tabular}

